Hopman, P., Rijken, M. Illness perceptions of cancer patients: relationships with illness characteristics and coping. Psycho-Oncology: 2015, 24(1), 11-18

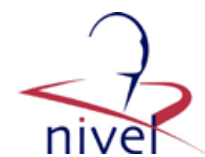

\begin{tabular}{|l|l|}
\hline $\begin{array}{l}\text { Postprint } \\
\text { Version }\end{array}$ & 1.0 \\
\hline Journal website & http://onlinelibrary.wiley.com/doi/10.1002/pon.3591/abstract \\
\hline Pubmed link & $\underline{\text { http://www.ncbi.nlm.nih.gov/pubmed/24891136 }}$ \\
\hline DOI & 10.1002/pon.3591 \\
\hline
\end{tabular}

This is a NIVEL certified Post Print, more info at http://www.nivel.eu

\title{
Illness perceptions of cancer patients: relationships with illness characteristics and coping
}

\author{
PETRA HopMAN, MiEKE RIJKEN
}

Netherlands Institute for Health Services Research (NIVEL), Utrecht, The Netherlands

\begin{abstract}
Objective: Illness perceptions have proven to be predictive of coping and adjustment in many chronically ill patients. However, insights into illness perceptions of cancer patients are scarce. The purpose of the present study was to explore how a heterogeneous sample of cancer patients perceive their illness. We also examined the relationships between cancer patients' illness perceptions, their illness characteristics, and their coping strategies.

Methods: Participants were 325 cancer patients of a generic nationwide longitudinal panel study among cancer patients in the Netherlands. They completed the revised Illness Perception Questionnaire (Winter 2011/2012) and the Mental Adjustment to Cancer Scale (Spring 2012). Analyses of variance and linear regression analyses were conducted.

Results: Patients' views on the chronicity of cancer vary, but many believe their illness to be long-lasting. Furthermore, they strongly believe the cancer treatment to be effective. People with skin cancer experience relatively little negative consequences $(p<0.01)$. Recently treated patients experience more negative consequences $(p<0.001)$ and perceive their illness as more chronic $(p<0.01)$. Surprisingly, neither perceptions of treatment control nor perceptions of personal control are related to specific ways of coping. However, more passive ways of coping were more often found in patients who perceived their illness as long-lasting, more emotionally burdening, and having more negative consequences.

Conclusions: Our findings suggest that cancer patients might benefit more from support to alleviate the perceived severity and threat of their illness rather than from (further) strengthening their control beliefs.
\end{abstract}

\section{INTRODUCTION}

Because of early detection and advanced treatment options, people with cancer generally live longer nowadays [1]. This, however, does not imply that the illness 
disappears from their lives. Physical problems such as fatigue and functional disability, as well as psychosocial problems, due to illness and its aggressive treatment often continue for years (e.g., works of Heins et al. [2] and Stein et al. [3]). Therefore, cancer is viewed as a chronic illness for an increasing number of cancer patients.

The problems mentioned earlier show how important it is for cancer patients to cope with their illness adequately and to face the challenges of their illness. People can cope with their illness in many ways [4-8], which may be more or less adaptive in specific situations. The way people perceive their illness affects the way they cope with it (e.g., works of Hagger and Orbell [9] and Weinman and Petrie [10]).

Therefore, it is interesting to examine to what extent illness perceptions of cancer patients are related to their coping strategies.

The present article aims to explore how (specific groups of) people with cancer perceive their illness and to what extent these perceptions are related to the way they are coping with their illness. Because illness perceptions are mental constructs that are open to change $[11,12]$, it might be possible for cancer patients to adopt (more) adaptive coping strategies through intervention in the way they perceive their illness. Previous research has demonstrated that illness perceptions of chronically ill patients can be successfully altered by short interventions [11, 12]. New insights might therefore add to actions and interventions that pay structural attention to the way cancer patients perceive their illness, thereby enabling them to cope with their illness more adequately.

\section{Illness perceptions}

According to the Common Sense Model of self-regulation by Leventhal et al. [13, 14], people make sense out of a health threat by developing their own cognitive representations about the illness and its treatment, on the basis of information (from health care professionals, family/friends, and media) and previous experiences with the illness. These cognitive representations or illness perceptions are generally formulated around the following dimensions: identity (the 'label' of the illness and the symptoms associated with it), cause (causal beliefs), timeline (acute-chronic or cyclical), control (the extent to which the illness is perceived as amendable by personal or treatment control), consequences (of the condition for the patient's life), coherence (patients' understanding of the illness), and emotional representations (extent to which the patient experiences symptoms of anxiety or depression) $[15,16]$. Theoretically, illness perceptions act as a framework for the coping strategies that individuals select (e.g., works of Hagger and Orbell [9], Weinman and Petrie [10], Heijmans [17], and Heijmans and de Ridder [18]). Empirical studies demonstrate their significance for coping with several chronic diseases [17, 19-21].

\section{Illness perceptions and coping among cancer patients}

Studies on illness perceptions regarding cancer not always concern the perceptions of cancer patients but also people's lay perceptions of cancer [22], health behavior to prevent cancer [23, 24], and responses to cancer screening (e.g., work of Hagger and Orbell [25]). Apart from one study focusing on a mixed group of cancer patients [26], known literature on the illness perceptions of people diagnosed with cancer is mainly limited to samples of people with specific types of cancer, such as breast [23, 27-30], head/neck [7, 31, 32], colorectal [33], and lung [34] cancer. However, reasoning from the Common Sense Model (which suggests that illness perceptions 
are shaped by past and present experiences) seems likely that patients with the same type of cancer have more similar perceptions because of their common experience of disease type. Indeed, Husson and colleagues [26] found more similar perceptions among patients with endometrial and Hodgkin lymphoma cancer than between these tumor groups and others. Other characteristics, such as illness duration and treatment status, might affect cancer patients' experiences and shape their illness perceptions as well. For instance, previous research has shown different levels of perceived personal control in short-term and long-term colorectal cancer survivors [33].

The relationship between cancer patients' illness perceptions and coping strategies has mainly been studied among patients with a specific type of cancer [28-30, 3537]. Buick [28], for example, found that breast cancer patients treated with chemotherapy (versus radiotherapy) reported more internal, self-blame, and environmental attributions and believed that their illness would last longer and have more serious consequences. Moreover, breast cancer patients treated with chemotherapy were more likely to suppress competing activities, mentally disengage, and show restraint, whereas patients treated with radiotherapy showed more acceptance. Rozema and colleagues [30] found a weak relationship between breast cancer patients' illness representations and coping strategies: only a perception of a more chronic timeline strongly related to (cognitive and behavioral) avoidance as a coping strategy. Furthermore, Llewellyn and colleagues [31] found a relationship between head and neck cancer patients' pretreatment beliefs about the negative consequences of their illness and post-treatment maladaptive (i.e., denial, substance use, and behavioral disengagement) and adaptive (i.e., use of planning, selfdistraction, and active coping) coping. These studies however were all conducted within samples of people with specific types of cancer. The inconsistent results provide no clear overall picture of the relationship between cancer patients' illness perceptions and coping.

\section{The present study}

The current research addresses the following research questions:

How do cancer patients perceive their illness, in terms of causes, timeline, control, consequences, coherence, and emotional representations?

Given that illness perceptions are formed by experience: to what extent do illness perceptions of cancer patients depend on the type of cancer, illness duration, and cancer treatment?

To what extent do illness perceptions relate to the way cancer patients are coping with their illness?

Although this study is mainly explorative in nature, we have formulated the following hypotheses with respect to the third research question: perceptions of one's cancer as being more controllable (by medical treatment and/or self-management) and more coherent (better understanding of the illness) relate to the use of more active coping strategies (i.e., moving toward the stressor), whereas perceptions of the illness as having more negative consequences and being more emotionally loaded relate to the use of more passive coping strategies (i.e., withdrawing from the stressor). 
Hopman, P., Rijken, M. Illness perceptions of cancer patients: relationships with illness characteristics and coping. Psycho-Oncology: 2015, 24(1), 11-18

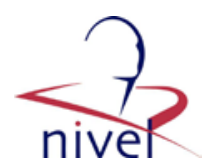

\section{METHODS}

\section{Participants and procedures}

For the purpose of this study, we analyzed data from the 'Panel Living with Cancer', which is a nationwide prospective panel study on patient perspective on cancer in the Netherlands. A random sample was drawn from the Netherlands Cancer Registry (NCR). Inclusion criteria were as follows: a diagnosis of cancer (all tumor types with an expected 5-year survival rate of $\geq 20 \%$ ) and being aged $\geq 18$ years at diagnosis. Exclusion criteria were as follows: a post-diagnosis time span of more than 15 years and the presence of distant metastases at time of diagnosis. This sample $(N=1500)$ was presented to the medical specialists involved in the care for these patients to check on additional exclusion criteria, such as patients' inability to participate because of severe mental disorder, intellectual disability, illiteracy, or terminal illness. A total of 893 patients were eligible for this study according to their medical specialists. Half of them $(N=452 ; 51 \%)$ gave informed consent to participate in the panel study. These panel members receive a questionnaire twice a year.

For this study, we used data of 325 panel members who had participated in the first survey of the panel study (Winter 2011/2012; 72\% response rate). Two hundred sixty-seven (82\%) of these respondents also participated in the second survey (Spring 2012), in which data on coping were collected. The study was carried out according to the precepts of the Helsinki Declaration, Dutch legislation on privacy, and the regulations of the Dutch Data Protection Authority.

\section{MEAsures}

\section{Illness perceptions}

To assess cognitive and emotional representations of cancer, the Dutch version of the revised Illness Perception Questionnaire (IPQ-R) was used [15]. The IPQ-R consists of seven scales: (a) Timeline: acute-chronic, (b) Timeline: cyclical, (c) Consequences, (d) Personal control, (e) Treatment control, (f) Illness coherence, (g) Emotional representations, as well as three Causal attributions scales (i.e.

Psychological attributions, Risk factors, and Immunity) and two single Causal attribution items. We did not use an Identity scale ('label' and presence of symptoms attributed to the illness) because it was not possible to compose one that is applicable to our total sample (i.e., people with different types of cancer). Items are scored on 5point Likert scales, ranging from 'strongly disagree' (1) to ‘strongly agree' (5). All scales demonstrated good internal reliability with Cronbach's alphas ranging from 0.60 to 0.91 (Table 2 ).

\section{Coping}

The Dutch version [8] of the Mental Adjustment to Cancer Scale (MAC) [5] was used to assess participants' coping with cancer. All 40 items are scored on 4-point Likert scales, ranging from 'This definitely does not apply to me' (1) to 'This definitely applies to me' (4). The MAC scale consists of five scales, measuring various dimensions: Fighting Spirit (16 items, $\alpha=0.79$ ), Helplessness/Hopelessness (6 items, $\alpha=0.79$ ), Anxious Preoccupation (9 items; $\alpha=0.73$ ), Fatalism ( 8 items, $\alpha=0.59$ ), and Avoidance (single item). 
Hopman, P., Rijken, M. Illness perceptions of cancer patients: relationships with illness characteristics and coping. Psycho-Oncology: 2015, 24(1), 11-18

\section{Patient and illness characteristics}

Age, gender, presence of one or more comorbid diseases (yes/no), and treatment for cancer in the past 12 months (yes/no) were derived from self-report. Type of cancer, post-diagnosis time span (on the basis of the date of diagnosis), and type of cancer treatment(s) were derived from the NCR. When NCR data were missing $(n=31)$, we imputed the self-reported data on these illness characteristics.

\section{Data analyses}

Descriptive statistics were computed to describe sample characteristics and IPQ-R scores (research question 1). To examine whether the illness perceptions of cancer patients depend on their type of cancer, post-diagnosis time span, and cancer treatment (research question 2), we conducted a series of analyses of covariance with Bonferroni post-hoc tests to test for significant differences between subgroups. We corrected for the following patient characteristics: age, gender, comorbidity, type of cancer, and post-diagnosis time span (if not being the independent variable itself). To determine the effects of illness perceptions on coping (research question 3), we conducted a series of multiple regression analyses. For each analysis, we included one MAC scale as the dependent variable and one IPQ-R scale as predictor, together with patient characteristics (age, gender, comorbidity, type of cancer, post-diagnosis time span, recent treatment for cancer, and type of cancer treatment). All analyses were performed using the statistical package Stata 12.

\section{RESULTS}

\section{Patient and illness characteristics}

The sample consisted of 161 men and 164 women aged between 21 and 89 years $(M=64.31 ; S D=12.21)$ (Table 1$)$. Breast cancer (25\%) and cancer of the digestive system (22\%) were most prevalent. Almost half of the participants (45\%) had a postdiagnosis time span of $2-5$ years, and $20 \%$ received cancer treatment at the moment of the first survey. Most participants (had) received only surgery or surgery in combination with some other form of treatment, respectively, 38\% and 33\%.

\section{[TABLE 1]}

Participants were representative for the target population (as derived from the NCR) with respect to gender and tumor type but were slightly older (54\% of the participants vs. $39 \%$ of the target population were aged $\geq 65$ years) and had a somewhat shorter post-diagnostic time span (55\% of the participants vs. $39 \%$ of the target population had a post-diagnostic time span of $<5$ years).

\section{Illness perceptions of the total sample}

Table 2 contains the means and distributions of the IPQ-R scale scores. It shows a relatively high mean and wide distribution on the scale 'Timeline: acute-chronic', compared with the scale 'Timeline: cyclical'. This indicates that many participants perceive their illness to continue for a long time but that there were also participants with another opinion in this respect. The high mean scores on the scales 'Treatment control' and 'Illness coherence' indicate that participants have a strong belief in the effectiveness of the cancer treatment and believe that they understand their illness rather well. It should be noticed that, in general, these patients perceive their personal control over the illness to be much lower than its controllability by medical 
Hopman, P., Rijken, M. Illness perceptions of cancer patients: relationships with illness characteristics and coping. Psycho-Oncology: 2015, 24(1), 11-18

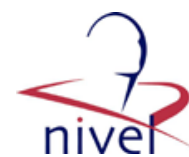

treatment. Regarding causal attributions, relatively low scores on the 'Psychological' scale indicate that participants do not perceive psychological factors to be a major cause of their illness. In contrast, they attribute their illness more to chance or bad luck, although there is some variety among the scores in this respect.

\section{[TABLE 2]}

\section{Illness perceptions of subgroups}

We also analyzed the IPQ-R scores for subgroups. Here, we only describe significant differences in scores between subgroups. Skin cancer patients $(M=2.30, S D=0.96)$ do not seem to perceive their illness as something that will drastically affect their lives, compared with patients with other types of cancer (consequences; $F[4$, $267]=3.69, p<0.01)$. Besides, skin cancer patients $(M=1.86, S D=0.80)$ less strongly perceive a bacteria/virus, pollution, and/or altered immunity as causing their illness, especially when compared with patients with a less prevalent type of cancer (i.e., category 'Other'; $M=2.43, S D=0.79 ; F[4,257]=3.32, p<0.05$ ).

Patients with different types of cancer vary in their personal control perceptions $(F[4$, $268]=2.52, p<0.05$ ), but post-hoc tests show no significant differences between specific subgroups. Breast cancer patients $(M=2.08, S D=0.70)$ quite strongly perceive psychological factors as a cause of their cancer-especially when compared with people with cancer of the skin $(M=1.65, S D=0.75)$ or the male reproductive organs $(M=1.76, S D=0.50 ; F[4,258]=4.49, p<0.01)$.

Regarding cancer treatment, patients who had recently been treated (i.e., within 12 months preceding data collection) perceive their illness as more chronic ( $M=3.42$, $S D=1.06$ ) and as more drastically affecting their lives (consequences; $M=3.10$, $S D=0.84)$ than patients who had not been treated recently $(M=2.93, S D=1.01 ; F[1$, $259]=14.34, p<0.001$ and $M=2.56, S D=0.79 ; F[1,260]=18.31, p<0.001$, respectively). Also patients who underwent cancer treatment(s) other than surgery perceive their illness as more chronic $(M=3.62, S D=0.98)$ and more drastically affecting their lives (consequences; $M=2.91, S D=0.84$ ) than patients who exclusively underwent surgical treatment $(M=2.88, S D=1.10 ; F[3,266]=3.91$, $p<0.01$ and $M=2.51, S D=0.86 ; F[3,267]=4.56, p<0.01$, respectively). Patients who underwent a combination of surgery and other cancer treatment(s) $(M=2.08$, $S D=0.72$ ) quite strongly perceive psychological factors as a cause of their cancerespecially when compared with patients who only underwent other cancer treatment(s) $(M=1.67, S D=0.58 ; F[3,258]=3.16, p<0.05)$.

\section{Illness perceptions as predictors of coping}

Table 3 shows that although cancer patients use different types of coping, they relatively often adopt the fighting spirit strategy. Moreover, the degree to which they adopt certain strategies is related to the way they perceive their illness (Table 4). More specifically, the more cancer patients perceive their illness as a chronic condition, as something that drastically affects their lives (consequences), and the more it elicits negative emotional responses, the more likely they are to adopt more passive ways of coping such as helplessness/hopelessness, anxious preoccupation, or fatalism. Interestingly, perceptions of control (personal or treatment) do not relate to the degree to which they use certain coping strategies. 
Hopman, P., Rijken, M. Illness perceptions of cancer patients: relationships with illness characteristics and coping. Psycho-Oncology: 2015, 24(1), 11-18

\section{[TABLE 3] [TABLE 4]}

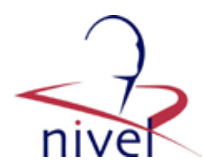

\section{DISCUSSION}

The present study aimed to explore the illness perceptions of cancer patients and to examine whether these perceptions relate to type of cancer, post-diagnosis time span, and treatment (timing and type). Additionally, the study aimed to examine the relationships between cancer patients' illness perceptions and their coping with the illness.

\section{Illness perceptions of people with cancer}

A remarkable finding was the relatively high mean score on the IPQ-scale 'Timeline: acute-chronic', especially when compared with the mean on Timeline: cyclical and earlier research among people with head/neck cancer $(M=2.51, S D=0.8$ [29]; $M=2.85, S D=0.73$ [30]) and breast cancer $(M=2.78, S D=0.94$ [34]). Many cancer patients seem to perceive their illness not so much as temporary but more as a condition that is chronic in nature. Although a substantial part of our sample had been diagnosed more than five years ago, in people's experience, the illness is not over yet. Another notable finding was the relatively low mean score on the IPQ-scale 'Personal control', when compared with other studies among cancer patients $(M=3.18, S D=0.71$ [34]; $M=3.13, S D=0.63$ [30]; $M=3.49, S D=0.71$ [38]). Perceived personal control is also poor when compared with perceived treatment control within our sample. This indicates that cancer patients' beliefs in the controllability of their illness by medical treatment are generally stronger than their personal control beliefs. This might be (partially) explained by our sample consisting of patients with no metastasis on time of diagnosis and/or a relatively long survival rate. Among patients with advanced cancer and/or a less favorable prognosis, treatment and personal control perceptions may differ less.

\section{Differences between subgroups}

Skin cancer patients do not seem to perceive their illness as something that drastically affects their lives. This is compatible with the fact that the majority of the skin cancer population is diagnosed with carcinoma, which has relatively mild treatment options and favorable prognoses. One in ten skin cancer patients suffers from melanoma, accounting for no less than $85 \%$ of the mortality due to skin cancer. However, although more research is needed, existing research shows that selfreported quality of life scores of patients with melanoma are similar to those of the normative population [39].

The relatively high mean scores on the IPQ-scales 'Timeline: acute-chronic' and 'Consequences' among patients who have recently been treated indicate that these people perceive their illness as something that will continue for a long time and will drastically affect their lives. This is understandable because these people are still in the active phase of the illness. The effectiveness of the treatment and the course of illness may be unclear at that point.

People who underwent another type of treatment than surgery believe their illness to be long-lasting and to drastically affect their lives. It might be that these patients had a poorer prognosis at the time of diagnosis than patients who exclusively underwent surgery.

Although the cross-sectional design of this study requires cautiousness, the fact that no effects of post-diagnosis time span on illness perceptions were found gives rise to 
the suggestion that illness perceptions become rather stable over time, although longitudinal research is necessary to confirm this idea. Illness perceptions of patients who were diagnosed 10 years ago are not essentially different from those of patients who were diagnosed 3 years ago. The current sample did not comprise cancer patients who were diagnosed very recently (within 12 months), which may be the phase that illness perceptions are generally formed [40].

\section{Illness perceptions and coping among people with cancer}

Cancer patients use different ways of coping, but the degree to which they use certain strategies largely depends on how they perceive their illness. Perceived chronicity of the illness is particularly related to the use of coping strategies-especially to those that could be considered as more passive strategies, such as anxious preoccupation and helplessness/hopelessness. These findings are partially compatible with earlier research [30, 31]. Additional analyses showed that the relationship patterns between illness perceptions and coping are comparable for different types of cancer. The absence of any relationship between illness perceptions and 'avoidance' as a coping style is however remarkable, given the fact that such associations have been found in other studies among breast cancer patients [29, 30]. In these studies, other scales were used to assess avoidance (i.e., COPE questionnaire and Utrecht Coping Questionnaire). The items of these scales mainly relate to behavioral and cognitive disengagement (e.g., 'I go to movies or watch TV, to think about it less'), whereas the avoidance item of MAC in our study (i.e., 'I don't really believe I had cancer') seems to refer more to sheer denial, which-being a rather extreme response-might be less susceptible to variation in perceptions.

\section{Strengths and limitations}

Participants of the current study represent a large proportion of the population of Dutch adult cancer patients. However, two groups are not represented: recently diagnosed patients and patients with a very poor prognosis at the time of diagnosis. It is likely that these patients' perceptions of their illness are different (e.g., high expectations about treatment control) from those of the patients we studied here. Although the absence of participants with a very recent diagnosis of cancer can be considered a limitation of the current study, the representation of patients who were diagnosed many years ago can be considered a strength-particularly in view of the fact that most research on cancer patients' coping focuses on relatively recently diagnosed cancer patients (up to 3 years, a maximum of 5 years post-diagnosis). Because more and more people survive cancer, a growing number has to live with the consequences of the illness and its treatment. A full understanding of coping on the long term is lacking, and therefore, it is important to examine illness perceptions and coping strategies of cancer patients who were diagnosed in the (distant) past. Another limitation of this study is that we were unable to make causal inferences about the relationship between people's illness perceptions and coping with cancer. Although we assessed the illness perceptions and coping strategies at different time points (with illness perceptions prior to coping), we are aware that time order is an essential but not sufficient condition when it comes to demonstrating causality. Furthermore, we did not examine the relationship of cancer patients' illness perceptions and coping strategies with adjustment to cancer. However, existingoften cross-sectional-studies within samples of people with specific types of cancer demonstrate significant relationships between illness perceptions and/or coping 
strategies with outcome variables such as distress, physical and mental health, and quality of life (e.g., the works of Rozema et al. [30] and others [31, 32, 36, 41]). To deepen our knowledge on the interplay between these constructs, longitudinal studies with more measuring moments over a substantial period of time are needed. At the moment of data collection, our panel was in the first year of its construction phase. Because members of the Panel Living with Cancer basically take part for several years, we will be able to conduct longitudinal analyses regarding illness perceptions and coping in the future.

The present study not only demonstrates how people with cancer in general perceive their illness (something that has not been extensively studied so far) but also how these illness perceptions relate to illness related characteristics. By including a heterogeneous sample of people with cancer, we could demonstrate that not only the type of cancer but also illness characteristics such as treatment (timing and type) impact on illness perceptions. Future research however might benefit from information on current cancer stage, because this might give us more information on people's prognoses - a factor that is likely to impact on their illness perceptions.

\section{Practical implications}

The current study provides insight into the relationship between cancer patients' illness perceptions and their coping strategies. Because illness perceptions can be changed, it may be possible for cancer patients to adopt (more) adaptive coping strategies through intervention on the way they perceive their illness [26, 32]. Our results might therefore contribute to the development of (generic) support programs for cancer patients that pay structural attention to the way these people perceive their illness and help them to cope with it. More specifically, interventions could focus on reducing distress and emotional problems by discussing the perceived chronicity of the illness and its impact on patients' lives (and resolve possible misconceptions). Our findings suggest that cancer patients might benefit more from support to alleviate the perceived threat of their illness than from support to (further) strengthen their control beliefs. Benefit could particularly be gained with people who are adopting coping styles that seem likely to be maladaptive in the long run, such as anxious preoccupation and helplessness/hopelessness. Cancer patients may be enabled to (better) adjust to their illness which, in turn, might positively affect patients' quality of life.

\section{CONCLUSIONS}

Many (former) cancer patients generally perceive their illness as a chronic condition and have a strong belief in the effectiveness of cancer treatment. Although cancer patients use different types of coping, the degree to which they adopt certain strategies depends on the way they perceive their illness. This knowledge may be used to develop (generic) support programs for cancer patients that pay structural attention to the way these people perceive their illness and, as a result, might enable them to more adequately cope with and adjust to the illness.

\section{ACKNOWLEDGEMENTS}

This study was financed by the Dutch Cancer Society. We would like to thank the Comprehensive Cancer Centre the Netherlands (IKNL) and Mirian Brink in particular for their contributions to the recruitment of panel members via the NCR 
Hopman, P., Rijken, M. Illness perceptions of cancer patients: relationships with illness characteristics and coping. Psycho-Oncology: 2015, 24(1), 11-18

and the data collection. Furthermore, we thank the advisory board and the panel members for their efforts and contributions to the Panel Living with Cancer.

\section{REFERENCES}

1 Signaleringscommissie-Kanker. Cancer in the Netherlands: trends, prognosis and implications for health care. / Kanker in Nederland: Trends, prognoses en implicaties voor zorgvraag. Amsterdam: Dutch Cancer Society / KWF Kankerbestrijding, 2004.

2 Heins MJ, Korevaar JC, Rijken PM, Schellevis FG. For which health problems do cancer survivors visit their general practitioner? Eur J Cancer 2013;49(1):211-218.

3 Stein KD, Syrjala KL, Andrykowski MA. Physical and psychological long-term and late effects of cancer. Cancer 2008;112:2577-2592.

4 Lazarus RS, Folkman S. Stress, Appraisal, and Coping. Springer: New York, 1984.

5 Watson M, Greer S, Young J, Inayat Q, Burgess C, Robertson B. Development of a questionnaire measure of adjustment to cancer: the MAC scale. Psychol Med 1988;18(1):203-209. DOI: 10.107/S0033291700002026.

6 Greer S, Watson M. Mental adjustment to cancer: its measurement and prognostic importance. Cancer Surv 1987;6(3):439-453.

7 Johansson M, Rydén A, Finizia C. Mental adjustment to cancer and its relation to anxiety, depression, HRQL and survival in patients with laryngeal cancer-a longitudinal study. BMC Cancer 2011;11:283.

8 Braeken APBM, Kempen GIJM, Watson M, et al. Psychometric properties of the Dutch version of the Mental Adjustment to Cancer Scale in Dutch cancer patients. PsychoOncology 2010;19(7):742-749.

9 Hagger MS, Orbell S. A meta-analytic review of the common-sense model of illness representations. Psychol Health2003;18(2):141-184.

10 Weinman J, Petrie KJ. Illness perceptions: a new paradigm for psychosomatics? J Psychosom Res 1997;42(2):113-116.

11 Petrie KJ, Cameron LD, Ellis CJ, Buick D, Weinman J. Changing illness perceptions following myocardial infarction: an early intervention randomized controlled trial. Psychosom Med 2002;64:580-586.

12 Moss-Morris R, Humphrey K, Johnson MH, Petrie KJ. Patients' perceptions of their pain condition across a multidisciplinary pain management program: do they change and if so does it matter? Clin J Pain 2007;23(7):558-564.

13 Leventhal H, Meyer D, Nerenz D. The common sense representation of illness danger. In Medical Psychology, Rachman S (ed.), Pergamon Press: New York, 1980.

14 Leventhal H, Nerenz D, Steele D. Illness representations and coping with health treats. In Handbook of Psychology and Health, Baum A, Singer J (eds). Erlbaum: New York, 1984; 221-252.

15 Moss-Morris R, Weinman J, Petrie K, Horne R, Cameron L, Buick D. The Revised Illness Perception Questionnaire (IPQ-R). Psychol Health 2002;17(1):1-16. DOI:

16 Weinman J, Petrie K, Moss-Morris R, Horne R. The Illness Perception Questionnaire: a new method for assessing the cognitive representation of illness. Psychol Health1996;11:431-445.

17 Heijmans $M$. The role of patients' illness representations in coping and functioning with Addison's disease. Br J Health Psychol 1999;4:137-149.

18 Heijmans M, de Ridder D. Assessing illness representations of chronic illness: explorations of their disease specific nature. J Behav Med 1998;21:485-503. DOI:

19 Scharloo M, Kaptein A, Weinman J, et al. Illness perceptions, coping and functioning in patients with rheumatoid arthritis, chronic obstructive pulmonary disease and psoriasis. J Psychosom Res 1998;44:573-585.

20 Scharloo M, Kaptein AA, Weinman J, Bergman W, Vermeer BJ, Rooijmans HGM. Patients' illness perceptions and coping as predictors of functional status in psoriasis: a 1year follow-up. Br J Dermatology 2000;142:899-907.

21 Moss-Morris R, Petrie KJ, Weinman J. Functioning in chronic fatigue syndrome: do illness perceptions play a regulatory role? Br J Health Psychol 1996;1:15-25. DOI: 
Hopman, P., Rijken, M. Illness perceptions of cancer patients: relationships with illness characteristics and coping. Psycho-Oncology: 2015, 24(1), 11-18

22 Figueiras MJ, Alves NC. Lay perceptions of serious illnesses: an adapted version of the Revised Illness Perception Questionnaire (IPQ-R) for healthy people. Psychol Health2007;22(2):143-158.

23 Decruyenaere M, Evers-Kiebooms G, Welkenhuysen M, Denayer L, Claes E. Cognitive representations of breast cancer, emotional distress and preventive health behaviour: a theoretical perspective. Psycho-Oncology 2000;9(6):528-536.

24 Cameron LD. Illness risk representations and motivations to engage in protective behavior: the case of skin cancer risk. Psychol Health2005;23(1):91-112. DOI:

25 Hagger MS, Orbell S. A confirmatory factor analysis of the revised illness perception questionnaire (IPQ-R) in a cervical screening context. Psychol Health2005;20:161-174.

26 Husson O, Thong MSY, Mols F, Oerlemans S, Kaptein AA, van de Poll-Franse LV. Illness perceptions in cancer survivors: what is the role of information provision? Psycho-Oncology 2013;22:490-498.

27 Anagnostopoulos F, Spanea E. Assessing illness representations of breast cancer. A comparison of patients with healthy and benign controls. J Psychosom Res 2005;58:327334.

28 Buick D. Illness representations and breast cancer: coping with radiation and chemotherapy. In Perceptions of Health and Illness, Petrie K, Weinmann J (eds). Harwood Academic Publishers: Singapore, 1997; 379-409.

29 Fischer MJ, Wiesenhaan ME, Does-den Heijer A, Kleijn WC, Nortier JW, Kaptein AA. From despair to hope: a longitudinal study of illness perceptions and coping in a psychoeducational group intervention for women with breast cancer. $\mathrm{Br} \mathrm{J}$ Health Psychol 2013;18(3):526-45.

30 Rozema H, Völlnick T, Lechner L. The role of illness representations in coping and health of patients treated for breast cancer. Psycho-Oncology 2009;18:849-857.

31 Llewellyn CD, McGurk M, Weinman J. Illness and treatment beliefs in head and neck cancer: is Leventhal's common sense model a useful framework for determining changes in outcome over time? J Psychosom Res 2007;63:17-26.

32 Scharloo M, Baatenburg de Jong R, Langeveld T, Velzen-Verkaik E, Doorn-op-den Akker M, Kaptein A. Quality of life and illness perceptions in patients with recently diagnosed head and neck cancer. Head Neck 2005;27(10):857-863.

33 Mols F, Denollet J, Kaptein AA, Reemst PH, Thong MS. The association between Type D personality and illness perceptions in colorectal cancer survivors: a study from the population-based PROFILES registry. J Psychosom Res 2012;73:232-239.

34 Hoogerwerf MA, Ninaber MK, Willems LN, Kaptein AA. "Feelings are facts": illness perceptions in patients with lung cancer. Respir Med 2012;106(8):1170-1176.

35 Dempster M, McCorry NK, Brennan E, Donnelly M, Murray L, Johnston BT. Do changes in illness perceptions predict changes in psychological distress among oesophageal cancer survivors? J Health Psychology 2011;16(3):500-509.

36 Gould RV, Brown SL, Bramwell R. Psychological adjustment to gynaecological cancer: patients' illness representations, coping strategies and mood disturbance. Psychol Health. 2010;25(5):633-46.

37 Vogel JJ, Godefroy WP, van der Mey AGL, le Cessie S, Kaptein AA. Illness perceptions, coping, and quality of life in vestibular schwannoma patients at diagnosis. Otol Neurotol 2008;29:839-845. DOI: 10.1097.

38 Giannousi Z, Manaras I, Georgoulias V, Samonis G. Illness perceptions in Greek patients with cancer: a validation of the Revised-Illness Perception Questionnaire. PsychoOncology 2010;19:85-92.

39 Holterhues C, Cornish D, van de Poll-Franse LV, et al. Impact of melanoma on patients' lives among 562 survivors: a Dutch population-based study. Arch Dermatol. 2011;147(2):177-185.

40 Leventhal H, Benyamini Y, Brownlee S, et al. Illness representations: theoretical foundations. In Perceptions of Health and Illness, Petrie K, Weinmann J (eds). Harwood Academic Publishers: Singapore, 1997; 19-45.

41 Stanton AL, Danoff-Burg S, Cameron CL, et al. Emotionally expressive coping predicts psychological and physical adjustment to breast cancer. J Consult Clin Psychol 2000;68(5):875-882. 


\section{TABLES AND FIGURES}

Table 1. Patient and illness related characteristics $(N=325)$

\begin{tabular}{|c|c|c|}
\hline & $\bar{N} N$ & $\%$ \\
\hline Patient characteristics & & \\
\hline \multicolumn{3}{|l|}{ Age (years) } \\
\hline $18-49$ & 34 & 10 \\
\hline $50-64$ & 116 & 36 \\
\hline $65-74$ & 110 & 34 \\
\hline$\geq 75$ & 65 & 20 \\
\hline \multicolumn{3}{|l|}{ Gender } \\
\hline Male & 161 & 50 \\
\hline Female & 164 & 50 \\
\hline \multicolumn{3}{|l|}{ Comorbidity } \\
\hline None & 105 & 32 \\
\hline One or more comorbid diseases & 203 & 62 \\
\hline Unknown & 17 & 5 \\
\hline \multicolumn{3}{|l|}{ Illness related characteristics } \\
\hline \multicolumn{3}{|l|}{ Type of tumor } \\
\hline Breast & 82 & 25 \\
\hline Digestive systema & 71 & 22 \\
\hline Male reproductive organsb & 59 & 18 \\
\hline Skinc & 41 & 13 \\
\hline Otherd & 69 & 21 \\
\hline Unknown & 3 & 1 \\
\hline \multicolumn{3}{|l|}{ Post-diagnosis time span (years) } \\
\hline $1-2$ & 35 & 11 \\
\hline $2-5$ & 145 & 45 \\
\hline $5-10$ & 85 & 26 \\
\hline $10-15$ & 29 & 9 \\
\hline Unknown & 31 & 10 \\
\hline \multicolumn{3}{|c|}{ Treatment for cancer (past 12 months) } \\
\hline Yes & 66 & 20 \\
\hline No & 245 & 75 \\
\hline Unknown & 14 & 4 \\
\hline \multicolumn{3}{|c|}{ Type of cancer treatment (recently or in the past) } \\
\hline Only surgery & 132 & 41 \\
\hline Surgery and other treatment(s)e & 120 & 37 \\
\hline
\end{tabular}




\begin{tabular}{|l||c||c|}
\hline & $\boldsymbol{N}$ & $\mathbf{\%}$ \\
\hline \hline Only other treatment(s)e & 49 & 15 \\
\hline No surgery or other treatment(s)e & 23 & 7 \\
\hline \hline Unknown & 1 & 0 \\
\hline
\end{tabular}

${ }^{a}$ Small bowel, large bowel, rectum, and anus.

${ }^{b}$ Prostate, penile, testicular, and others.

${ }^{c}$ All types of skin cancer.

${ }^{d}$ Less prevalent types of cancer were clustered into the category 'Other'. This category includes the cancer types 'Blood, lymphatic, and bone marrow cancer' $(n=18 ; 6 \%)$, 'Urinary tract cancer' $(n=16 ; 5 \%)$, 'Head and neck cancer' $(n=13$; $4 \%)$, 'Cancer of the female reproductive organs' $(n=13 ; 4 \%)$, and 'Other' $(n=9$; $3 \%)$.

${ }^{e}$ In the current study, the category 'other treatment(s)' comprises radiotherapy, chemotherapy, hormonetherapy, and immunotherapy.

Table 2. Means and distributions of the revised Illness Perception Questionnaire scales

\begin{tabular}{|c|c|c|c|}
\hline $\begin{array}{c}\text { Revised Illness Perception Questionnaire } \\
\text { scales }\end{array}$ & $M$ (SD) & $N_{\text {items }}$ & $\begin{array}{c}\text { Cronbach's } \\
\text { alpha }\end{array}$ \\
\hline Timeline: acute-chronic & $\begin{array}{l}2.99 \\
(1.05)\end{array}$ & ||6 & 0.91 \\
\hline Timeline: cyclical & $\begin{array}{l}2.38 \\
(0.89) \\
\end{array}$ & | 4 & 0.83 \\
\hline Consequences & $\begin{array}{l}2.69 \\
(0.82)\end{array}$ & ||6 & 0.80 \\
\hline Personal control & $\begin{array}{l}2.65 \\
(0.68) \\
\end{array}$ & ||6 & 0.72 \\
\hline Treatment control & $\begin{array}{l}3.36 \\
(0.72) \\
\end{array}$ & $\mid 5$ & 0.73 \\
\hline Illness Coherence & $\begin{array}{l}3.80 \\
(0.69)\end{array}$ & $\mid 5$ & 0.74 \\
\hline Emotional representations & $\begin{array}{l}2.47 \\
(0.91) \\
\end{array}$ & ||6 & 0.92 \\
\hline \multicolumn{4}{|l|}{ Causal attributions } \\
\hline Psychological & $\begin{array}{l}1.94 \\
(0.70)\end{array}$ & ||6 & 0.88 \\
\hline Risk factors & $\begin{array}{l}2.20 \\
(0.61) \\
\end{array}$ & ||7 & 0.70 \\
\hline Immunity & $\begin{array}{l}2.26 \\
(0.75) \\
\end{array}$ & ||3 & 0.60 \\
\hline Chance or bad luck & $\begin{array}{l}3.65 \\
(1.06)\end{array}$ & $\| 1$ & - \\
\hline
\end{tabular}




\begin{tabular}{|c|c|c|c|}
\hline $\begin{array}{c}\text { Revised Illness Perception Questionnaire } \\
\text { scales }\end{array}$ & $M$ (SD) & $N_{\text {items }}$ & $\begin{array}{c}\text { Cronbach's } \\
\text { alpha }\end{array}$ \\
\hline Accident or injury & $\begin{array}{l}1.65 \\
(0.68)\end{array}$ & $\mid 1$ & - \\
\hline
\end{tabular}

Table 3. Means and distributions of the Mental Adjustment to Cancer subscales

\begin{tabular}{|l|l|l|l|l|}
\hline $\begin{array}{c}\text { Mental Adjustment to Cancer } \\
\text { subscales }\end{array}$ & $\begin{array}{c}\text { Sum score } \\
\text { (SD) }\end{array}$ & $\begin{array}{c}\text { Scale score } \\
\text { (1-4) }\end{array}$ & $\boldsymbol{N}_{\text {items }}$ & $\begin{array}{c}\text { Cronbach's } \\
\text { alpha }\end{array}$ \\
\hline \hline Fighting Spirit & $44.94(6.13)$ & 2.81 & 16 & 0.79 \\
\hline \hline Helplessness-Hopelessness & $9.79(2.61)$ & 1.63 & 6 & 0.79 \\
\hline \hline Anxious Preoccupation & $18.27(3.80)$ & 2.03 & 9 & 0.73 \\
\hline Fatalism & $17.46(3.43)$ & 2.18 & 8 & 0.59 \\
\hline Avoidance & $1.83(0.77)$ & 1.83 & 1 & - \\
\hline
\end{tabular}

Table 4. Relationship of illness perceptions (revised Illness Perception Questionnaire) with coping strategies (Mental Adjustment to Cancer) corrected for patient characteristics*

\begin{tabular}{|c|c|c|c|c|c|c|}
\hline & & \multicolumn{5}{|c|}{ "Mental Adjustment to Cancer Scales } \\
\hline & & \begin{tabular}{|c} 
Fighti \\
ng \\
Spirit
\end{tabular} & $\begin{array}{c}\text { Helplessness/Hopeless } \\
\text { ness }\end{array}$ & \begin{tabular}{|c|} 
Anxious \\
Preoccupati \\
on
\end{tabular} & $\begin{array}{c}\text { Fatalis } \\
\mathbf{m}\end{array}$ & $\begin{array}{l}\text { Avoidan } \\
\text { ce }\end{array}$ \\
\hline \multirow{11}{*}{$\begin{array}{l}\text { IPQ- } \\
\text { scale } \\
\text { s }\end{array}$} & \multirow{3}{*}{$\begin{array}{l}\text { Timeline: } \\
\text { acute- } \\
\text { chronic }\end{array}$} & \multirow{3}{*}{ n.s. } & $B=0.34$ & $B=0.33$ & $\begin{array}{l}B=0.2 \\
6\end{array}$ & \multirow{3}{*}{ n.s. } \\
\hline & & & $p<0.001$ & $p<0.001$ & $\begin{array}{l}p<0.00 \\
1\end{array}$ & \\
\hline & & & $n=226$ & $n=219$ & $n=207$ & \\
\hline & \multirow{3}{*}{$\begin{array}{l}\text { Timeline: } \\
\text { cyclical }\end{array}$} & \multirow{3}{*}{ n.s. } & \multirow{3}{*}{ n.s. } & $B=0.33$ & $\begin{array}{l}B=0.2 \\
3\end{array}$ & \multirow{3}{*}{ n.s. } \\
\hline & & & & $p<0.001$ & $p<0.00$ & \\
\hline & & & & $n=217$ & $n=205$ & \\
\hline & \multirow{3}{*}{$\begin{array}{l}\text { Consequenc } \\
\text { es }\end{array}$} & \multirow{3}{*}{ n.s. } & $B=0.40$ & $B=0.50$ & $\begin{array}{l}B=0.2 \\
4\end{array}$ & \multirow{3}{*}{ n.s. } \\
\hline & & & $p<0.001$ & $p<0.001$ & $\begin{array}{l}p<0.00 \\
5\end{array}$ & \\
\hline & & & $n=227$ & $n=220$ & $n=208$ & \\
\hline & \begin{tabular}{|l|} 
Personal \\
control
\end{tabular} & n.s. & n.s. & n.s. & n.s. & n.s. \\
\hline & $\begin{array}{l}\text { Treatment } \\
\text { control }\end{array}$ & n.s. & n.s. & n.s. & n.s. & n.s. \\
\hline
\end{tabular}




\begin{tabular}{|c|c|c|c|c|c|}
\hline & \multicolumn{5}{|c|}{ Mental Adjustment to Cancer Scales } \\
\hline & \begin{tabular}{|l|} 
Fighti \\
ng \\
Spirit
\end{tabular} & $\begin{array}{c}\text { Helplessness/Hopeless } \\
\text { ness }\end{array}$ & \begin{tabular}{|c|} 
Anxious \\
Preoccupati \\
on \\
\end{tabular} & $\begin{array}{c}\text { Fatalis } \\
\text { m }\end{array}$ & $\begin{array}{c}\text { Avoidan } \\
\text { ce }\end{array}$ \\
\hline \multirow{3}{*}{$\begin{array}{l}\text { Illness } \\
\text { coherence }\end{array}$} & \multirow{3}{*}{ n.s. } & \multirow{3}{*}{ n.s. } & $B=-0.25$ & $\begin{array}{l}B=-0 . \\
19\end{array}$ & \multirow{3}{*}{ n.s. } \\
\hline & & & $p<0.001$ & $p<0.01$ & \\
\hline & & & $n=217$ & $n=205$ & \\
\hline \multirow{3}{*}{$\begin{array}{l}\text { Emotional } \\
\text { representatio } \\
\text { ns }\end{array}$} & \multirow{3}{*}{ n.s. } & $B=0.42$ & $B=0.53$ & \begin{tabular}{|l}
$B=0.2$ \\
3
\end{tabular} & \multirow{3}{*}{ n.s. } \\
\hline & & $\mid p<0.001$ & $p<0.001$ & $\begin{array}{l}p<0.00 \\
1\end{array}$ & \\
\hline & & $n=223$ & $n=217$ & $n=205$ & \\
\hline \multirow{3}{*}{\begin{tabular}{|l|} 
Causes: \\
psychologic \\
al \\
attributions \\
\end{tabular}} & \multirow{3}{*}{ n.s. } & \multirow{3}{*}{ n.s. } & $B=0.29$ & \multirow{3}{*}{ n.s. } & \multirow{3}{*}{ n.s. } \\
\hline & & & $p<0.001$ & & \\
\hline & & & $n=215$ & & \\
\hline \begin{tabular}{|l|} 
Causes: risk \\
factors
\end{tabular} & n.s. & n.s. & n.s. & n.s. & n.s. \\
\hline \multirow{3}{*}{$\begin{array}{l}\text { Causes: } \\
\text { immunity }\end{array}$} & \multirow{3}{*}{ n.s. } & \multirow{3}{*}{ n.s. } & $B=0.25$ & \multirow{3}{*}{ n.s. } & \multirow{3}{*}{ n.s. } \\
\hline & & & $p<0.001$ & & \\
\hline & & & $n=215$ & & \\
\hline $\begin{array}{l}\text { Causes: } \\
\text { chance/bad } \\
\text { luck }\end{array}$ & n.s. & n.s. & n.s. & n.s. & n.s. \\
\hline \begin{tabular}{|l|} 
Causes: \\
accident/inju \\
ry
\end{tabular} & n.s. & n.s. & n.s. & n.s. & n.s. \\
\hline
\end{tabular}

- n.s., not significant.

- * Patient characteristics for which we corrected were age, gender, comorbidity, type of cancer, post-diagnosis time span, treatment for cancer, and type of cancer treatment. Table 4 exclusively shows regression coefficients of models that are significant at the level of $p<0.001$, with the exception of three models that are significant at the level of $p<0.005$ (i.e., timeline: acute-chronic-helplessness/hopelessness, consequences-fatalism, and illness coherence-fatalism). 